\title{
EL CABILDO CATEDRALICIO Y EL EPISCOPADO CORDOBÉS, DEL ANTIGUO AL NUEVO RÉGIMEN (1789-1883)
}

\author{
POR ‘ \\ José García-Cuevas Ventura \\ Universidad de Córdoba
}

\section{RESUMEN}

Con frecuencia, la asignatura más difícil para los obispos de Antiguo y del Nuevo Régimen fue el trato con los cabildos catedralicios. En las siguientes páginas se analizan los contactos mantenidos entre los ocupantes de la sede de Osio y su senado, desde 1789, año de la preconización de Antonio Cabaliero, y 1883, término del pontificado de Ceferino González. A partir de los comedios de la pasada centuria, el binomio obispo-cabildo se saldó a favor del primero, y la unidad de acción alcanzó su clímax.

\begin{abstract}
The Cathedral Chapter and the episcopate of Córdoba, from Old to New Regime (I789-1883).

Frequently, dealing with the cathedral chapters was the more difficult question for the bishops during Old and New Regime. In the following pages, the contacts between the occupants of Osio's see and its senate are studied, from 1789, year of preconization of Antonio Caballero, to 1883, the pontificate's end of Ceferino González. From the middle of the past century, the binomy bishopchapter was solved in the benefit of the first, and the unity of action reached its climax.
\end{abstract}


La importancia del tema en que nos adentramos la ha sugerido Cuenca Toribio, al señalar que la asignatura de ordinario más difícil para los obispos del Antiguo y Nuevo Régimen fue el trațo con los cabildos catedrales' ${ }^{1}$. El interés se acrecienta al constatar que, en los comedidos de la pasada centuria, se operó en este duelo secular, una ruptura de su habitual equilibrio inestable a favor del episcopado ${ }^{2}$. Las páginas que siguen, pretenden confirmar la solidez de estas afirmaciones ${ }^{3}$.

\section{CABAllero: LA ARMONIA (1789-1796)}

La preconización de Antonio Caballero y Góngora en 1789 debió causar complacencia entre los miembros del grupo catedralicio, sabedores de su pericia y discreción, aquilatadas durante el desempeño de la canonjía lectoral en el mismo capítulo (1753-1775). El ilustre prieguense sentía, por su parte, una honda satisfacción ante el retorno a la antigua ciudad califal.

La administración de las rentas de la mitra fue, quizás, la primera de las muchas demostraciones de confianza que el anterior arzobispo de Bogotá prodigaría hacia el clero capitular durante su pontificado cordobés ${ }^{4}$. Aunque el ceremonial de recibimiento, visita y juramento, encuadrado en los rígidos moldes establecidos en 1777, no propiciase la espontaneidad, el indisimulado entusiasmo de los prebendados no quedaría defraudado con el tiempo. El flamante obispo pretendió aquistarse desde un principio el afecto de su senado, elogiando el esmerada gestión de los fondos que le había encomendado. Asimismo, al emprender su primera visita pastoral, en 1790, le expresó su deseo

1 Pueblos y gentes de Córdoba, Cordoba, 1989, 110 . (La galería episcopal incluida en este libro -cap. IV-cs, por su concisión, obligada referencia en estas líncas). Cfr. Sociología del episcopado español e hispanoamericano (1789-1985), Madrid, 1986, del mismo autor.

2 CuEnCA TORIBIO, J.M., Iglesia y burguexía en la España liberal, Madrid, 1979, 136.

3 Para mayor jlustración, remitimos a nuestra Tesis Doctoral, aún inédita, dírigida por eł profesor Cuenca, y titulada: El Cabildo catedralicio cordobés desde la Revolución a la Restauración (1788-1882), Córdoba, 1994, en particular, 334-371. (En ella podrú hallarse, v.gr, información pormenorizada sobre los capitulares responsabilizados de la administración diocesana, las elecciones simultáneas y episcopales, junto a los períodos de sede vacante).

4 La reconstrucción del mismo fue tarea acometida por el cronista José María Rey Díaz, materializada en un erudito ensayo biográfico. Gran parte de los datos que ahora suministramos aparecen allí referidos: "Una figura de relieve en la Historia de Córdoba: D. Antonio Caballero y Góngora, Arzobispo-Virtey de Nueva Granada", Boletín de la Real Academia de Córdoba (BRAC.) 5 ([923), $25-38 ; 6(1923), 53-76 ; 7(1923), 10 !-113$.

De la Iglesia Andaluza Hispania Sacra 48 (1996) 
de "emplearse en su obsequio desde todas las distancias"5. La experiencia ulterior no desmintió esta lisonjera y tópica declaración de intenciones.

Habiendo tenido ocasión de desplegar sus innegables dotes diplomáticas en tierras americanas, no encontró especial dificultad en activar los mecanismos apropiados para esquivar roces y confrontaciones gratuitas con la corporación eclesiástica, moneda corriente en la España de la segunda mitad del setecientos. El éxito de su empresa se debió, en buena medida, a la resuelta voluntad de no lesionar prerrogativas ni entrometerse en competencias ajenas. Quiso reconciliar al Cabildo con su propia vocación, convirtiéndolo en auténtico cuerpo consultivo. Y, en efecto, le hizo partícipe de sus preocupaciones, solicitando su parecer en múltiples materias. Por si fuera poco, aquella labor de mediación y arbitraje de que hiciera gala en el arzobispado de Santa $\mathrm{Fe}$ fue recuperada en pro de la armonía -siempre precaria- entre los dos cabildos locales, como ocurrió en $1794^{6}$.

Curtido en el virreinato de Nueva Granada, demostró ser un auténtico gobernante, capaz de encarar los asuntos más embarazosos, sobre todo, cuando peligraba el status de la Iglesia diocesana, a la que, con notable altura de miras, consideró como un todo. Fue muy significativo su celo en la salvaguarda de los intereses económicos de la catedral. Por eso, al entablarse un expediente sobre la administración y división de diezmos, se ofreció para la defensa de la Mesa Capitular ${ }^{7}$. Supo anteponer el patrimonio común a su hacienda personal. Ejemplar y desinteresada resultó, al respecto, su conducta ante la demanda de alhajas por parte de la superioridad. Al disponer su inventario, quiso preservar algunas piezas, acordando su rescate con dinero efectivo y supliendo lo necesario con sus propios bienes ${ }^{8}$.

Era, además, proverbial su liberalidad. Por ello, no ha de resultar extraño su desvelo por lograr el incremento del patrimonio de la fábrica y de la magnificencia del ceremonial catedralicios. Con toda justicia, la corporación supo reconocer "lo mucho que se esmera en obsequiar, y en aumentar el Culto divino en esta Santa Yglesia"9. En otro terreno, también brindó su ayuda al deán Fernández de Cordoba para la fundación de las Escuelas Pías, proyecto que

5 Archivo de la Catedral de Córdoba (ACC.).- Actas Capitulares. Cabildo pleno ordinario, 7 de octubre de 1790 , t. 92 , f. 184 y. La notificación de las visitas pastorales suministran ejemplos de esquisitez en el trato.

6. Véase Archivo Municipal de Córdoba (AMCO.).-Actas Capitulares. Cabildo, 9 de septiembre de 1794, caja 157, s.f. 188.

7 Vd. ACC.-Actas Capitulares. Cabildo pleno ordinario, 11 de octubre de 1790, t. 92, f. 187 -

\& Ibid. Cabildo Pleno, 27 de mayo de 1795, t. 94, s.f.

9 lbid. Cabildo pleno ordinario, 7 de julio de 1790, t. 92, f. 159 v. 
cuadraba plenamente con las propuestas ilustradas, tan caras para un prelado que cifraba en la instrucción pública la panacea de casi todos los males.

Su carácter complaciente quedó también de manifiesto en el auto de reducción de las misas del punto, complejo asunto que halló cauce de resolución en $1793^{10}$. La afabilidad se combinó aquí, en armónica síntesis, con el referido talante reformador. No en vano, una de sus mayores preocupaciones era el arreglo de la Colecturía. En este negocio, como en tantos otros, solicitó la ilustración de su consejo. Tales demostraciones no supusieron ninguna tregua en la lucha secular del colectivo religioso en defensa de sus derechos, como se evidenció en materia de provisiones. Recordemos, además, que en 1792 y 1794 , se promulgaron unos importantes decretos sobre el cumplimiento de las capellanías de San Pedro.

Atendiendo a las continuas muestras de consideración y avalado por el ejemplar desempeño de su ministerio pastoral, el Cabildo solicitó en 1796 el valimiento regio a fin de alcanzar la concesión del capelo cardenalicio para Caballero. La Corona, correspondiendo también a su inquebrantable lealtad, accedió a dichas súplicas. A no dudarlo, la iniciativa habría sido exitosa, si la muerte del mitrado no hubiera sobrevenido tan de improviso. Cuando parientes, colaboradores y favorecidos dispusieron la celebración de unas exequias, los capitulares admitían que "si bien debe honrar siempre como acostumbra, la memoria de sus prelados, con particularidad debe hacerlo por la del Difunto, que guardó tan buena harmonia con este cabildo, y fue tan bienhechor de esta Santa Yglesia y su fabrica"11. El comentario era cabal. En su oración sagrada, después impresa, el magistral Amat y Cortés no escatimó elogios para el fina$\mathrm{do}^{12}$.

\section{AYESTERÁN: LA CONTINUIDAD (1796-1805)}

Agustín de Ayesterán y Landa, obispo auxiliar del arzobispado hispalense, tomó posesión de la sede cordobesa en el mes de agosto de 1796, aunque su arribo se demoró hasta octubre. Desde el primer instante, quiso mantener el

10 Tales misas, dotadas desde antnõo por buen número de fieles, debían oficiarse diariamente, en sufragio de sus almas.

If ACC.- Actas Capitulares. Cabildo pleno, 24 de noviembre de 1796, t. 95, s.f.

12 "Oración fúnebre, que en las solemnes exequias que se hicieron a la gloriosa memoria del Excelentisimo é flustrisimo Señor D. Antonio Cavallero y Góngora, arzobispo, obispo de Córdoba, y Cavallero Prelado Gran Cruz de la Real Distinguida Orden Española de Carlos III, en la Capilla de Nuestra Señora de Villa-viciosa de la Santa Iglesia Catedral de dicha Ciudad el día 29 de noviembre de 1796 dixo el Dr, D. Nicolás Amat y Cortés, canonigo magistral de la misma Santa Iglesia", Córdoba, (1796).

De la lglesia Andaluza

Hispania Sacra 48 (1996) 
clima de entendimiento y cordialidad alcanzado por su predecesor, solicitando la hermandad con el Cabildo. Al emprender su primera visita pastoral, le expreso su intención de complacerle "en todo destino y ocasiones"13. Sus deseos se vieron pronto correspondidos, pues, con asiduidad, los prebendados sondearon su opinión, antes de tomar cartas en asuntos de especial entidad.

La primacía de los factores económicos en esta coyuntura histórica es manifiesta ${ }^{14}$. Aunque nuestro parecer resulte algo sorprendente, el reclamo de arbitrios al ordo clericalis reforzó los lazos de unión entre los centros de poder diocesano, como se puso de manifiesto en 1798, con motivo de la contribución conjunta al préstamo de tres millones ${ }^{15}$. La semejanza con los usos de su antecesor quedó patente cuando Ayesterán, conocedor de los apuros de la Hacienda Capitular, franqueó doscientos mil reales reintegrables del fondo de reparo de obras, como anticipo al Estado en la guerra contra Gran Bretaña. Como no podía ser menos, su senado aplaudió la iniciativa. Ambos compartieron, además, idéntica actitud obstruccionista ante la operación desamortizadora. El prelado, dominador insuperable de la técnica dilatoria, influyó poderosamente en la estrategia capitular, formando un frente común para contrarrestar, en la medida de lo posible, la pérdida de su nivel económico y social ${ }^{16}$.

El contencioso que acaparó las relaciones institucionales en el cruce de las centurias fue, empero, el polémico plan de prebendas. Si bien, las exigencias de la superioridad podrían haber frustrado el buen acuerdo imperante, don Agustín desestimó la supresión de pieza eclesiástica alguna. El cuerpo catedral le pidió que continuara "favoreciéndole en quanto sea compatible con las Reales Ordenes"17. Quizá por eso, en 1802, mostró vivo interés porque no quedase descuidada la dotación de su primera silla. También hizo algunas dádivas, similares a las prodigadas en tiempos de Caballero.

Aunque comparado con el de éste, su caracter resultase un tanto indolente -desventaja compensada por la ausencia de personalismo-, Ayesterán se mostró muy interesado en la búsqueda de bienes dotales para el Hospicio o Casa de Misericordia, cuyo establecimiento se le había confiado. Para evacuar el asunto, mantuvo un estrecho contacto con el Cabildo, pretendiendo la apli-

\footnotetext{
13 ACC. -Actas Capitulares. Cabildo pleno, 6 de octubre de 1797, t. 95, s.f.

14 Advirtamos que, en et engranaje busrocrático, la autoridad episcopal se consolida como correa de transmisión de las disposiciones superiores.

15 Véase MOYA ULLDEMOLINS, J.M. y SÁNCHEZ GARCtA, L.E., "Contribución ordinaria y extraordinarin del clero cordobés a la Corona durante el reinado de Carlos IV", Axerquia 6 (1983), 47 ss.

16 SÁNCheZ GarCía, L.E., D. Agustín de Ayesterán y Landa, obispo de Córdoba (1796-1805), Córdoba, 1978, 53 (Memoria de Licenciatura inédita); CUENCA TORIB1O, J.M., Plteblos y gentes..., 107.

17 ACC-Acras Capitulares. Cabildo pleno, 22 de febrero de 1800 , t. 95, s.f.
} 
cación de algunas obras pías a tal objeto. Asimismo, en el terreno social, fueron sensibles ante el problema de abastecimiento ocasionado por la hambruna de $1804^{18}$.

El 20 de marzo de 1805 fallecía Ayesterán y Landa, poniéndose fin a un pontificado de transición, como lo definiera el profesor Cuenca ${ }^{19}$. El antiguo obispo titular de Botra había otorgado dos canonjías a sus sobrinos, los hermanos José Luis y Juan Ramón de Ubillos. Este último fue arcediano de Pedroche y secretario de Cámara, convirtiéndose en habitual acompañante en los viajes pastorales. Unido a su tío desde la infancia, recibió una esmerada formación que, unida a su modestia y reserva, le convirtieron en un excelente colaborador, adiestrado en las funciones de gobierno ${ }^{20}$. Eficaz enlace entre el palacio episcopal y la catedral, contó con un enorme peso específico dentro y fuera de ella, siendo numerosas las empresas por él impulsadas, como la reforma educativa de Seminario o el plan de curatos.

\section{TREVILLA: LOS RIESGOS DE UNA PERSONALIDAD MARCADA (1805-1832)}

El largo mandato de Pedro Antonio Trevilla coincidió casi de forma exacta con la crisis final del Antiguo Régimen. El anterior canónigo de Toledo estaba ya avezado al trato con las instituciones catedralicias. La pronta admisión en hermandad y la ratificación de la concordia suscrita en 1670 con el obispo Alarcón, sobre elecciones beneficiales fueron los frutos más tempranos cosechados en su resuelto propósito de mantener unas satisfactorias relaciones con su senado. La intención de dotar al templo matriz con una sala capitular más digna debió causar entre los prebendados lógica satisfacción y, puede que en algunos, hasta envanecimiento. La realidad ulterior hizo del todo inviable el proyecto, pero el clero catedral pudo calibrar el genio enérgico del nuevo ocupante de la silla de Osio, bastante diferente a su grisáceo predecesor ${ }^{21}$.

Trevilla notificó puntualmente el inicio de sus visitas pastorales, sin que el contacto epistolar quedase siquiera interrumpido durante sus periplos. En toda ocasión se mostró solícito ante los problemas que aquejaban al capítulo, como

18 Vd. LOPEz MORA, F., Pobreza y sociedad en Córdoba (1750-1900): de la caridad a la beneficencia píblica. Córdoba, 1992, II, 599 (Tesis Doctoral inédita).

19 Pueblos y gentes..., 105.

20 Vd. PAvón, F, de B., Necrologías de varios comemporáneos distinguidos dadas á liz con anterioridad en varias fechas y publicaciones y ahora coleccionadas, Córdoba, 1892, 9-14; ACC. Actas Capitulares. Cabildo de canónigos, sede vacante, 16 de diciembre de 1833 , t. 110, f. 202 v.$216 \mathrm{v}$.

21 Una interesante documentación alusiva al tema, se conserva en el Archivo General de Obispado de Córdoba (AGOC.). "Cabildo Catedral", leg. s.n., s.f.

De la Iglesia Andaluza Hispania Sacra 48 (1996) 
se desprende, por ejemplo, de sus certeras resoluciones atañentes a la reducción de misas y al incremento estipendial de las pertenecientes a Obras Pías.

La coordinación de actuaciones se intensificó notablemente durante la francesada ${ }^{22}$. Aunque la postura mantenida ante la presión fiscal anterior sea un válido referente inmediato, la unidad -casi uniformidad- de miras lograda en la fase bélica contaba, en verdad, con pocos precedentes. La indefensión de la clericatura propició el aunamiento de esfuerzos para formar un cuerpo compacto y, quizá por ello, menos vulnerable. El Cabildo supo relegar algunas de sus reivindicaciones más arraigadas, pero reaccionó, por ejemplo, ante las incorrecciones formales del gobernador del obispado y al percibir algunas inobservancias en el cumplimiento de la concordia sobre provisiones simultáneas.

La autoridad episcopal, transmisora de las disposiciones de la autoridad política y militar, reclamó la opinión de su consejo en asuntos de la mayor trascendencia, como la elección de un sacerdote que asistiese a la convocatoria de Bayona, los nombramientos efectuados por la Junta Suprema o la investidura del nuncio con facultades extraordinarias. Resulta difícil imaginar que un hombre tan resoluto se encontrase azarado a la hora de dirimir tales controversias. Sin embargo, quiso contar con el respaldo de la corporación, contrastando su dictamen personal con los juicios de algunos de sus miembros más preeminentes, partícipes, por añadidura, de idéntico sentir. Para ilustrar esta sintonía, recordemos que la respuesta a la Comisión de Cortes -octubre de 1809-, fue rubricada por el obispo y los canónigos Ventura y Ugalde. El doctoral Millán pudo ser, igualmente, el redactor de la famosa carta pastoral de 1810 , en que se proponía el sometimiento a José $\mathrm{I}^{23}$. Asimismo, los pormenores relacionados con la solicitud de Cortes generales, en 1812, corroboran la existencia de un tándem compuesto por los ocupantes de las canonjías penitenciaria y doctoral, que seguidamente mencionaremos, al que, en ocasiones, se suma el racionero Garrido. El ocaso tributario y las reiteradas exacciones aplicadas a los fondos diocesanos contribuyeron, de modo indirecto, a consolidar esta atípica unidad institucional.

El equipo se vio seriamente afectado por las represalias, al término de la contienda. La comunidad catedralicia interpuso su valimento ante la Regencia y la Audiencia de Granada, preocupada por la suerte de su pastor, a quien se había encausado por sospechas de infidencia. A partir de entonces, fue nece-

22 Un acercaniento a la actuación del obispo Trevilla en tal coyuntura, lo oliece VAzQUEZ. LESMES, R., "Episcopado y Guerra de la Independencia en Córdoba", BRAC. 125 (1993), 13)-42.

23 Sea como fuere, su conterido cuadra con el talante de Trevilla, amante de la paz y de las transacciones, tan afecto, por lo demás, a la aseveración paulina sobre el origen divino del poder, Cuenca Toribio, J.M., Pueblos y gentes.... 111. 
sario rebatir con tenaz persistencia cualquier imputación sobre su conducta. Es ésta una de las claves para interpretar el sentido de algunas actuaciones conjuntas durante el reinado fernandino, especialmente en sus fases autoritarias. Ambos brindaron apoyo doctrinal y económico para garantizar el éxito de las directrices marcadas por la superioridad. El elemento religioso fue, de nuevo, puntal de los planes políticos, como expresión del más genuino estilo regalista.

El obispo continuó demandado el parecer del Cabildo, que le asesoró en materia tan compleja como el arreglo del plan de estudios del Seminario, la promoción de su cuerpo docente, la simplificación de pruebas para los colegiales, las dispensas matrimoniales, la censura de publicaciones o la recaudación de diezmos. La corporación eclesiástica solicitó, a su vez, el asenso episcopal ante algunas propuestas económicas, como la venta de bienes inmuebles. Trevilla facilitố también la apetecida reunión de varias capellanías.

La armonía que había presidido las relaciones institucionales conoció un serio deterioro en 1817, enturbiada por el nuevo reglamento administrativo de las rentas decimales, aunque el prelado, queriendo contrarrestar la animadversión capitular, asumió la responsabilidad del sucedió. De temperamento pacífico y amante de las transacciones, salió airoso de numerosos lances, gracias a su asombrosa habilidad. Con la probable intención de limar asperezas, regaló un precioso frontal de plata y bronce para el altar mayor. Por otro lado, en los comienzos de la década "ominosa", exhorto a la reconciliación, asegurando su intercesión por los capitulares desterrados. Al final de sus días, dispuso la confección de seis capas de raso y donó su pectoral más valioso, poniendo broche de oro a unas relaciones nunca exentas de dificultades. Murió el día 15 de diciembre de 1832, complacido, no obstante, por haber satisfecho una de sus prioridades.

Tras su arribo a las diócesis, Pedro Antonio Trevilla encontro unos colaboradores incodicionales pertenecientes a la "generación ilustrada". El elenco no muy amplio- estuvo presidido por dos cualificados personajes, ya aludidos: el penitenciario Manuel María de Arjona y el doctoral Diego Millán López de Gordoa, quienes, dada su comunión de ideas, entablaron una estrecha amistad con el obispo, no circunscrita a la esfera profesional. Como acabamos de advertir, sus servicios fueron muy importantes durante la ocupación francesa. No pudo contar, sin embargo, por mucho tiempo con tan fieles intérpretes de sus planes pastorales, pues ambos fallecieron en los comedios del pontificado -1820-, y Millán permanecía exiliado desde el término de la guerra. No obstante, se valió de la activa cooperación de sus propios sobrinos, introducidos mediante elección simultánea en el capítulo cordobés. El protagonismo de estos individuos superó, en numerosos extremos, al de su tío. No se produjo

De la Iglesia Andaluza Hispania Sacra 48 (1996) 
dejación de autoridad sino, más bien, la contitución de un eficaz gobiemo sinódico, cimentado en el nepotismo. Juan Trevilla, con pequeños paréntesis, ejerció el oficio de provisor y poderista. Andrés, el de obrero mayor de la fábrica. Todo apunta a que fue éste el personaje más influyente, "el verdadero obispo y el que todo lo manejó y dispuso"24. Lograda la canonjía doctoral, su preeminencia dentro de la corporación no se eclipsó tras la desaparición de su valedor. José María, el tercero de los hermanos, pareció heredar habilidad, intuición y ductilidad, ejercitadas desde su juventud en la administración diocesana. Aunque desempeñó ya entonces las funciones de secretario de cámara y gobierno, el despliegue de su actividad se produciría bajo los pontificados de Tarancón y Alburquerque.

\section{BONEL: UNA AUSENCIA CON CLAROSCUROS (1834-1847)}

Comenzaba una época en la Contemporaneidad española, capaz de generar, por imperativo de su propia dinámica interna, una modificación sustancial en las relaciones Iglesia-Estado. La diócesis cordobesa iba a estar presidida en sus primeros tramos por destacados representantes del sector altoeclesial "colaboracionista" con el gobierno liberal ${ }^{25}$. La apuesta por un porvenir de entendimiento y concordia con el Nuevo Régimen fue un elemento que, por fuerza, delimitó el campo de acción capitular durante su despliegue. Aludiremos en primer término al pontificado de Juan José Bonel y Orbe.

Com venía siendo ya práctica habitual, el obispo prócer hizo votos por la solidez de sus futuros vínculos con la agrupación catedralicia. En una carta alusiva a los poderes para su toma de posesión, previno que "nuestras relaciones han de ser mas frequentes"26. Poco después, en la reglamentaria visita de ofrecimiento, no ocultó "sus deseos de vivir siempre en intima union con el Cabildo"27. Prescindiendo de su probable ganga de convencionalismo, no contamos, en verdad, con argumentos suficientes para cuestionar su autenticidad. En cualquier caso, amparados en tan halagüeñas ofertas y sabedores de su grande ascendiente, los capitulares no dudaron siquiera un instante al encomendarle los trámites conducentes a la provisión de la chantría y de tres me-

\footnotetext{
24 Maraver y Alfaro, L., Historia de Córdoba (siglo XIX, I), (Córdoba), s.d., (año 1848), s.p.

25 Vd. CUENCA TORIBIO, J.M., Iglesia y burguesía..., 95-99.

26 ACC.- Actas Capitulares. Cabildo de canónigos, sede vacante, 2 de enero de 1834, t. ! I0, f. 5 v.

27 Ibid. Cabildo pleno, 24 de marzo de 1834, t. 110 , f. 71 v. Cfi. MARTín LOPEZ, M.R.E., $D$. Juan José Bonel y Orbe (1782-1857). Biografia y pensamiento de un prelado andaluz, Córdoba. 1984, 106 (Memoria de Licenciatura inédita).
} 
dias raciones, asunto realmente apremiante, dada la escasez de prebendados. Aunque el encargo tuvo un complejo desarrollo, cosechó el fruto apetecido ${ }^{28}$.

Se ha subrayado -creemos que con ligereza- el empeño del prelado granadino por servir a los intereses de la Iglesia diocesana. Nuestras investigaciones nos inducen a matizar la afirmación de que, pese a su alejamiento físico, "mantuvo siempre una relación afectiva con el cabildo y sus problemas"29. En efecto, no faltaron las fricciones que desmienten, al menos en parte, cualquier descripción idílica de tales contactos. Llegamos a percibir, incluso, cierto recelo ante la potestad episcopal, ocasionado, como tantas otras veces, por la toma de decisiones unilaterales en materias de gestión conjunta o privativa de la institución religiosa ${ }^{30}$.

El obispo censuró durante su corta estancia cordobesa, en 1839, el canto del "Admirable", pues, aunque fuese una práctica inveterada, no excitaba la devoción y, además, se interpretaba con desentono ${ }^{33}$. Mayor repulsa suscitó el acuerdo de que el clero parroquial concurriese por separado a la procesión del Corpus. Los capitulares más celosos juzgaron la medida como un ultraje a las "preeminentes prerrogativas" de la catedral ${ }^{32}$.

En 1840 se acrecentó el malestar con la real orden que autorizaba al medio racionero Gutiérrez de León para continuar percibiendo sus rentas mientras permanecía en la Corte, considerada como una flagrante violación del derecho común eclesiástico. La diputación del Punto y los canónigos de oficio, infiriendo que Bonel estaba persuadido de que la comensalidad era una de las causas canónicas que dispensaban la residencia, optó por acatar la disposición, dejando en blanco Jas casillas del cuadrante, donde se consignaban las obligaciones corales. A pesar de todo, el Cabildo se dirigió a don Juan José encareciéndole la conservación de los derechos recíprocos ${ }^{33}$. En prevención, quizá, de probables malentendidos, los prebendados recordaron, asimismo, su derecho de intervenir en cualquier diligencia encauzada a la modificación del ri-

28 Ibid., 113, 134. No serí ocioso el recuerdo de la actividad desplegada por Bonel en las juntas y comisiones encargadas de proyectar las apetecidas reformas eclesiásticas, como prócer en 1834 y senador en 1837. CARCEL ORTI, V., Políica eclesial de los gobiernos liberales españoles (18301840). Pamplona, 1975, 465.

29 MARTÍN LóPEZ, M.R.E., op. cit., 109.

30) A los rifirrafes epistolares de Bonel con los insumisos canónigos, ya ha aludido don José Manue! Cuenca en Pueblos y gente.s..., 113.

3 ACC.-Actas Capitulares. Cabildo pleno, 29 de mayo de 1839, t. 112, f. 41 v 44.

32 Ibid. Cabildo pleno extraordinario, 29 de mayo de 1839 , t. 112, f. 44-45 v.; AGOC.- Despacho ordinario. Cordoba capital, 19 (I831-1842), s,f.

$3 \mathrm{ACC}$-Actas Capitulares. Cabildo pleno, 17 de marzo de 1840, t. 112, f. 13v.-24.

De la Iglesia Andaluza Hispania Sacra 48 (1996) 
tual litúrgico, sin disimular su contrariedad cuando los planes episcopales no coincidían con los propios ${ }^{34}$.

A finales de los cuarenta, se incrementó la cooperación, entreviendo el grupo eclesiástico que la mediación obispal era necesaria para resolver la cuestión del culto y clero. Sin embargo, otra prueba documental de sus tiranteces se encuentra en la solicitud cursada a Bonel, el 28 de mayo de 1847, para que apoyase la exposición que con la misma fecha hacía llegar al ministro de Gracia y Justicia, reclamando el abono de la cantidad destinada al templo matriz $^{35}$. El Cabildo, con un tono que más bien parece una recriminación del absentismo del prelado de Pinos del Valle, Ie recordó con insistencia los irrenunciables deberes inherentes a su ministerio pastoral. En la respuesta a su misiva, datada el 6 de junio, el interpelado quiso disipar cualquier sombra de duda sobra la legitimidad de su conducta ${ }^{36}$. En cualquier caso, la cercanía de Bonel al establishment no resultó insignificante para los intereses capitulares, en unos tiempos, por lo demás, en que se buscaba acomodo con el moderantismo. Así, por ejemplo, la condonación de las deudas del deanato a la Real Capilla, en 1845, fue un importante logro debido a su ascendiente, que puso fin a cerca de un decenio de continuos sinsabores.

Entre los prebendados que ejercieron alguna tarea de gobierno, hemos de mencionar al racionero Joaquín María Villavicencio, gobernador eclesiástico, designado para desempeñar el provisorato y la vicaría general, e investido como parte de la dignidad episcopal. Su indiscutible preeminencia quedó reforzada por la confluencia de dos factores de peso: la lejanía del pastor y el afecto que ambos se profesaban desde su etapa formativa. De esta manera, pudo hacerse con el timón diocesano, convirtiéndose en el personaje clave de la etapa. En el otro extremo, el canónigo Rafael de Lara, que, paradójicamente, también gozaba de un notable predicamento en la Corte isabelina, pareció capitanear el descontento de un sector del cuerpo catedralicio, reacio al mitrado.

Dada su reputación en las esferas gobernantes, Bonel y Orbe fue destinado a la sede primada. En su pastoral de despedida admitía -a destiempo- sus largas y frecuentes ausencias, llegando a reconocer sus nocivos efectos ${ }^{37}$.

34 Ibid. Cabildo pleno, 31 de agosto de 1841 , t. 112, f. 55 v.-58 v.

35 ACC.-Mesa Capinular, leg. 3!40, 17.

36 Id.

37 La epístola está fechada en Madrid, a primero de noviembre de 1847. No era la primera vez en que Bonel se despedía de su senado. Preconizado para el arzobispado de Granada en 1838, tuvo ocasión de manifestar, ya entonces, los sentimientos que le producía la separación y la especial predilección en que tenía al Cabildo. La presentación, como es sabido, no fue reconocida por la Santa Sede.

De la Iglesia Andaluza Hispania Sacra 48 (1996) 
Quizá para repararlos, en 1857 se concedio a la mezquita-catedral el título de basílica menor, por excitación de aquel obispo que coronó su rutilante carrera con un capelo.

\section{TARANCÓN: CARA Y CRUZ DE UN CORTESANO (1847-1857)}

La acefalía del último quindecenio había dejado impresa su huella. El doctoral de la catedral vallisoletana, Manuel Joaquín Tarancón y Morón, sujeto de singulares virtudes y honoríficos antecedentes, fue el primer eclesiástico que pasó a engrosar la hornada episcopal de 1847-1849. Preconizado en el 47, pospuso su entrada en el territorio diocesano, embargado por sus trabajos como consejero extraordinario de la sección de Gracia y Justicia. Era, en verdad, como ha advertido Cuenca Toribio, un candidato "excelente para ejercer funciones de autoridad y representación en una España que buscaba a toda costa un eje sustentador en la "moderación" 38 .

Sin embargo, hemos de admitir con cierto desencanto que, durante este pontificado, no desplegó sus capacidades para solventar los problemas que atenazaban a la grey. Era un prelado cortesano, y su labor, por pura lógica, resultó grisácea. El juicio adverso que mereció de Ramírez de las Casas-Deza, el más prolífico escritor cordobés ochocentista, es, en esencia, coincidente con el de Juan Lucas del Pozo, quien pergeñó el bosquejo biográfico de numerosos clérigos afincados en la urbe andaluza ${ }^{39}$. Sin alzaprimar el valor de Io anecdótico, algunos acaecimientos presagiaron el clima distendido y cordial en que se desenvolvieron las relaciones institucionales, más fluidas que en el mandato precedente. Antes de su arribo a la ciudad, Tarancón entabló ya contacto epistolar con su senado para disponer unas rogativas por el Papa y evacuar las consultas previas a la definición dogmática del misterio de la Inmaculada Concepción.

Aunque sus deseos no siempre fueron colmados, el Cabildo quiso extraer el mejor partido de las importantes conexiones de su flamante obispo, confiándole muchas de sus inquietudes. La asignación del culto y clero era, por aquellas fechas, el contencioso que más le absorbía, pues no había logrado aún

\footnotetext{
38 La Iglesia española ante la revolución liberal, Madrid, 1971, 114; vd. "Biografín del Emmo. Excmo. Illmo. y Rmo. Sr. D. Manuel Joaquín Tarancón y Morón, carđenal presbítero de la Sta. Iglesia Romana. Arzobispo de Sevilla. Senador del Reino, Caballero Gran Cruz de la Real y Distinguida Orden española de Carlos III, del Consejo de S.M \&, que falleció en Sevilla el df́ 25 de agosto de 1862", Sevilla, 1862.

3) Biografia y memorias especialmente literarias, Córdoba, 1977, 137, 173, 181; Rasgos biográficess y fisionómicos, s.d., s.p.

De la Iglesia Andaluza

Hispania Sacra 48 (1996)
} 
el abono de los atrasos. Por eśo, no dudó un instante a la hora de encomendar al pastor, residente en Madrid, la mediación ante la Soberana, poniéndole al corriente de los perjuicios experimentados por tal causa ${ }^{40}$. Si bien, el asunto no se resolvió de forma inmediata, la acuciante necesidad de alcanzar un incremento presupuestario aconsejaría el redoblamiento de la acción conjunta en los años venideros. Contra todo pronóstico, la suma de esfuerzos no se saldó con espectaculares resultados, aunque tampoco quedó estéril. Los frutos más granados se cosecharían en los inicios del siguiente pontificado.

Como no podía ser menos, las relaciones también gravitaron alrededor de la aplicación efectiva de las disposiciones concordatarias. No en balde, Tarancón había intervenido efizcamente en el estudio de sus bases ${ }^{41}$. La catedral pretendió asegurar el futuro de los racioneros, perfilando, a un tiempo, las obligaciones de los beneficiados. Sin embargo, por no prestarles el debido acatamiento, los sucesivos reglamentos confeccionados para perfilar el funcionamiento de este nuevo cuerpo tuvierón una desigual eficacia. Recordemos que durante esta época se acentúa el papel del episcopado como transmisor de los dictámenes de la superioridad pólitica. El obispo de Córdoba debía ser hombre experimentado en estos cargos, conocidas sus hábiles gestiones en la Junta Eclesiástica.

Evidentemente, la comunicación no quedó ceñida a tales materias. Asî, por ejemplo, don Manuel Joaquín advirtió al Cabildo la conveniencia de responsabilizarse de la administración de los bienes devueltos, oferta a la que, en principio, éste era renuente. Es bastante probable, además, que intercediese, a comienzos de los cincuenta, para acelerar la provisión de las canonjías de oficio vacantes. Durante el bienio progresista, Tarancón y Morón, miembro ad perpetuum de la Cámara Alta, participó en la discusión de la base segunda del proyecto constitucional, oponiéndose al plan de la desamortización general. Su postura fué más resuelta que la de su consejo, aunque ambos compartieran idénticos intereses. Desde luego, sorprende la descoordinación en un asunto de tanta envergadura.

Cuando el obispo fue presentado para la archidiócesis hispalenses, los capitulares más lúcidos quizás fueran conscientes del auténtico significado de su pontificado cordobés, mero peldaño en su brillante cursus honorum, completado con la promoción a una sede metropolitana. Decían adiós a un personaje, cuyos dictámenes y, sobre todo, su cooperación tanto habían reclamado. Sin embargo, casi todos apetecían la llegada de un verdadero pastor. Acaecido su óbito en 1862, el capítulo, que ya había tenido ocasión de tributarle su home-

40 ACC.-Correspondencia, t. 15, 293.

41 Sobre los trabajos de la Junta mixta, vd. PÉrez Alhama, J., La Iglesia y el Estado español. Estudio histórico-jturítico a través del Concordato de 1851, Madrid, 1967, 252-63. 
naje al ser investido con la dignidad cardenalicia, reconoció las buenas y amistosas relaciones mantenidas con el difunto, y los beneficios dispensados durante el decenio en que ocupara la silla de $\mathrm{Osio}^{42}$.

\section{ALBURQUERQUE: UN PASTOR (1857-1874)}

Las esperanzas de los prebendados cordobeses se vieron colmadas tras la preconización de Juan Alfonso de Alburquerque y Weiron, anterior mitrado abulense, pues pronto iban a subsanarse las fatales consecuencias del absentismo. Durante su gobiemo, que abarca la fase postrera de la monarquía isabelina y el ciclo de la Gloriosa, las relaciones con el Cabildo fueron armónicas y muy constructivas. A decir verdad, el mérito fue recíproco.

El clero catedralicio acató las iniciativas del prelado murciano con asombrosa disponibilidad. Hemos de advertir, no obstante, que tal actuación adquiere sus auténticos perfiles en la corriente abierta con el tournant de Mastai y, en especial, tras la conclusión del Concordato de Bravo Murillo. El alcance del acuerdo diplomático suscrito entre el Estado español y la Santa Sede quedaba expresado en su artículo quince, al remarcar el cese de "toda inmunidad, exención, privilegio, uso ó abuso que de cualquier modo se haya introducido en las diferentes iglesias de España en favor de los mismos Cabildos con perjuicio de la Autoridad ordinaria de los Prelados"43. Reiteremos, pese a todo, el incondicional respaldo de la corporación a la enérgica labor del obispo, persuadida de su conveniencia. Como contrapartida, éste supo mostrar en todo instante una gran sensibilidad ante los problemas que la aquejaban.

Alburquerque fue una figura arquetípica del episcopado isabelino, afanado todo él en una vasta obra de reconstrucción y reorganización administrativa ${ }^{44}$. Los capitulares le debieron, por ejemplo, el orden y la regularidad del culto, la exactitud en la asistencia a los divinos oficios. Tampoco esquivó el arreglo de las dotaciones personales de los ministros y empleados de la fábrica. Consciente de que cualquier mejora en este terreno habría de ostentar el sello episcopal, la comunidad eclesiástica se rebajó a un segundo plano, limitándose a secundar sus propuestas. La unidad de acción, apuntada ya en el pontificado precedente, alcanzaría ahora su clímax, pero el binomio Obispo-Cabildo se saldó a favor del primero.

$$
\text { v. }
$$

42 ACC.- Actas Capitulares. Cabildo extraordinario, 27 de agosto de 1862, t. 117, f. 283 v. 284

43 Estas ideas fueron reiteradas en la real cédula (31-VII-1852) dirigida al episcopado, para proceder a la reforma o formación de los nuevos estatutos catedralicios.

44 CUenca ToRibio, J.M., La Iglesia española..., 85 ss. 
Desde 1640, en tiempos de fray Domingo Pimentel, no se había realizado una visita pastoral al templo matriz. El 15 de septiembre de 1861, tras un paréntesis de doscientos veintiún años, don Juan Alfonso quiso concluir en la catedral su periplo por el territorio diocesano. Durante su reconocimiento, consideró necesaria la reforma de algunas prácticas que no contaban con apoyatura legal. Las minuciosas instrucciones del obispo ordenancista atañían, sobre todo, al obrero mayor, a los encargados de las capillas y a los diputados de veintena. Pudo apreciar, asimismo, la inadecuada administración de las Obras Pías, dictando doce mandatos para ponerles eficaz remedio ${ }^{45}$.

El canónigo Ricardo Miguez apostilló, al reseñar el acto, "la pronta y leal cooperación del clero que en la actualidad cuenta la Diócesis y muy especialmente la del Ilmo. Cabildo que, comprendiendo y estimando el buen deseo y constantes desvelos de su prelado, no solamente no le ha servido de rémora para llevar á efecto sus acuerdos y disposiciones, sino que, en todo cuanto de ellos ha dependido, le facilitaron los medios de realizarlos"46. Más tarde, manifestaría la "deferencia y respeto con que (el Cabildo) solia acojer sus determinaciones, encaminadas todas al mejor govierno y mayor esplendor de esta corporación por cuya prosperidad tan vivamente se interesaba"47. El secretario de Camara hacía una atinada descripción de la realidad. No ha mucho, ese control hubiese sido interpretado como una inadmisible injerencia, pero en el seno capitular se habían producido importantes cambios cualitativos, debido, sobre todo, al influjo de factores externos. En este ambiente distendido, Alburquerque solicitó la ilustración de su senado para proceder al arreglo de la circunscripción diocesana. Los prebendados supieron calibrar su trascendencia, y nombraron una comisión encargado de la elaboración del proyecto, que incluyó un atinado examen sobre agregaciones y desmembraciones ${ }^{48}$.

Por lo que atañe a la religiosidad popular, el obispo resolvió algunas aspiraciones preteridas, como demostró mediante el valimiento interpuesto en su Visita ad limina de 1861, decisivo para la consecución de un importante rescripto pontificio sobre la devoción a San Rafael y los Santos Mártires. Recordemos, además, su empeño por dotar la fiesta del Corpus Christi con un ceremonial permanente, y su indesmayable voluntad catequística.

Alburquerque, que también manifestó la necesidad de establecer una normativa estable que rigiese el funcionamiento de los beneficiados, ratificaba en

\footnotetext{
45 ACC.- Obras Pía., leg. I 130 , s.f. Recordemos, al respecto, que uno de los frutos cosechados tras la visita ad Limina de 1861 , fue el auto de condonación y absolución por haber invertido cantidades de algunas fundaciones en el levantamiento de las cargas de otras.

45 Boletín Eclesiástico de Obispado de Córdoba (BEC.) 54 (1861), 223.

47 ACC.- Actas Capitulares, Cabildo, 27 de agosto de $1863,1.117$, f. 363.

48 Vd. ACC.-Correspondencia, t. 16, 339.
} 
1865 el parecer capitular, decretando la anulación de cualquier diligencia conducente a la alteración de sus reglamentos ${ }^{49}$. Sin embargo, tales pretensiones no resultaron enteramente exitosas. El impulso remozador se dejó sentir en la propia fábrica catedralicia, con la mejora de algunas dependencias o la retirada del enjalbegado de los arcos, descubriendo así sus bellas dovelas dicromáticas. La restauración, empero, quedó paralizada al suprimirse las consignaciones.

En lo concerniente a la evolución política, formaron una piña, dispuestos a no regatear esfuerzos para robustecer el Trono. Así se percibió, por ejemplo, ante la declaración de guerra al imperio marroquí, en 1859, y al acceder, en 1866, al descuento gradual de sus haberes. Amenazada la "unidad católica" tras el triunfo de la Septembrina, se intensificó la acción conjunta, elevando una exposición a las Cortes sobre la libertad de cultos. Lucharon contra el proselitismo protestante, repudiaron el juramento de la Constitución de 1869 y demandaron las cantidades adeudadas. No obstante, el prelado mostró mayor pragmatismo que su senado con ocasión de la investidura de Amadeo de Saboya. En 1872, el Cabildo se adhirió a la protesta contra el proyecto de ley sobre el presupuesto de obligaciones eclesiásticas. El arbitraje de una posible solución al problema del culto y clero reclamaba una cooperación aún más estrecha.

Asimismo, desde el vértice del XIX, los capitulares se brindaron unánimes a la exaltación del papado, secundando las iniciativas prelaticias. Por ello, aplaudieron, verbi gratia, la pronta difusión de la encíclica Quanta Cura (1864) y el Syllabus, refutaron el proyectado reconocimiento del reino de Italia, y expresaron sus fervientes deseos por la declaración dogmática de la infabilidad pontificia.

Los más directos colaboradores de Alburquerque, agraciados con la concesión de alguna prebenda, procedían de sus anteriores destinos y formaban una pequeña clientela. Pero, sin duda, los intérpretes más eficaces de sus ambiciosos planes apostólicos provenían de tierras abulenses, donde había ocupado -según apuntamos- su sede (1854-1857). Nos referimos a los hermanos orensanos Miguez y Carrasco: Ricardo, Benito y Manuel, El primero desplegó mayor actividad que los dos restantes; fue secretario de cámara y gobierno, visitador general y arcediano titular. Como director del Boletín Eclesiástico,

49 "Como la época en que vino S.E. era aun de transición de un derecho escrito á otro derecho escrito, y el personal antiguo había sido sustituido por el personal del concordato, tuvo que organizar y casi crear el servicio de la Iglesia con arreglo á las necesidades y circunstancias de los tiempos, en union y de acuerdo con el Ilmo. Cabildo", Boletín Eclesiástico extraordinario de la diócesis de Córdoba, Sede Vacante. Dedicado a la memoria del Excho. é Ilmo, Sr. Doctor D. Juan Alfortso de Alburquerque, dignisimo obispo que fué de la misma, Cordobn, 1875, 27.

De la Iglesia Andaluza Hispania Sacra 48 (1996) 
contribuyó desde sus páginas al reforzamiento del poder episcopal, uno de los logros más importantes de la mencionada publicación ${ }^{50}$. Benito, que había sido fiscal diocesano, catedrático y director espiritual del Seminario de Avila, presidió algunas asociaciones del voluntariado, auténtico eje vertebrador del programa pastoral para los laicos.

Don Juan Alfonso expiró el día 13 de marzo de 1874, habiendo distribuido sus pontificales, con criterios bastantes equitativos, entre las iglesias de Orihuela, Avila y Córdoba. El Cabildo, deudor de numerosas muestras de afecto, suscribiría el mencionado recuerdo de Ricardo Miguez, quien, al describir el carácter de su valedor, admitió haber recibido siempre "á sus consultas, prontas y acertadas respuestas; en sus fundadas quejas, justas y reparadoras disposiciones; en sus dudas, sábias y meditadas soluciones (...) Nada omitia, de todo cuidaba; previsor, prudente, activo y celoso hasta la nimiedad, si así nos es permitido hablar, de todo se ocupaba, á todos atendia"51 .

La merma del protagonismo capitular durante este período fue paralela al refuerzo episcopal, como adelantábamos en las consideraciones introductorias. Quedaba en pie una honda reorganización interna en las anquilosadas estructuras de la diócesis.

\section{GONZÁLEZ: EL ESFUERZO RESTAURADOR (1875-1883)}

El pontificado cordobés de fray Ceferino González y Díaz-Tuñón es, en no corta medida, continuación lógica del anterior. Desde el mismo momento de su traslado, en 1875, las relaciones del obispo renunciatario de Málaga con el Cabildo fueron enteramente amistosas y fecundas. Los prebendados reafirmaron su fidelidad a los proyectos de su brillante prelado. Como contrapartida, González, necesitado de la colaboración incondicional del alto clero para sacar adelante su ambicioso plan restaurador, se esmeró en complacer a su senado aun en los más ínfimos detalles. Así, por ejemplo, favoreció la consecución del rescripto de la Santa Sede, que les concedía el uso perpetuo de medias y alzacuello morado; supo proteger con sabias órdenes el legado artístico catedralicio, sin descuidar la salvaguarda de su rico depósito documental: en 1877, confirió una capellanía para el arreglo del archivo-biblioteca. Igualmente, transcurridos dos años, otorgó un reglamento para los cantores y ministros. Durante su mandato, se afianzaría el prestigio y la autoridad episcopal.

50) Cfr. CARCEL ORT1, V., "Los Boletines oficiales eclesiásticos de España", Hispania Sacra XIX (1966), 45-85.

s) Boletín Eclestástico extraordinario..., 9. 
La restauración social y religiosa se articuló en una doble estrategia, contemplando la captación de minorías y de masas. La primera implicó el remozamiento del escolasticismo, empleado esta vez como contraveneno de las doctrinas "disolventes". La segunda se plantificó mediante el encuadramiento del proletariado en asociaciones confesionales, que les inmunizaran frente a las ideas revolucionarias. Como veremos, el Cabildo secundó enteramente las directrices pastorales, convencido de la pertinencia de tal operación.

En efecto, promulgada la encíclica Aeterni Patris (1879), fray Ceferino requirió la cooperación capitular en la restauración filosófico-tomista, que encontaría en el clérigo dominico a su principal impulsor en el desigual panorama cultural hispano. El capítulo, persuadido desde hacía tiempo de la urgente necesidad de regenerar el cuerpo social, acogió de forma entusiasta la propuesta. Ya que el sistema escolástico aspiraba a convertirse en el método formativo de los futuros sacerdotes, resulta muy lógico que fuesen, precisamente, los capitulares ligados a la actividad docente en el Seminario de San Pelagio, sus más ardorosos apologistas.

Por contra, las excelentes cualidades organizativas y el eminente sentido práctico de González no le aconsejaron el concurso de la referida entidad para la fundación del primer Círculo Católico en Córdoba ${ }^{52}$. Ni siquiera juzgó oportuno concederle una participación expresa en la junta directiva de la capital. Sin embargo, no dudó al recabar el influjo moral y material de arciprestes y curas párrocos, por considerarlo más directo y eficaz. No obstante, algunos de sus más cualificados componentes apoyaron la empresa, aunque de forma ocasional, nada sistemática, en el menester más conforme a su vocación: el adoctrinamiento. El Cabildo, cuyo protagonismo en las tareas asistenciales y benéficas había sido incuestionable, no tomó parte, pues, ni en la creación ni en la difusión de los Círculos, permaneciendo al margen del movimiento social auspiciado por la Iglesia docente en los inicios del canovismo. Fue aquélla una obra del todo asociada a la personalidad del indesmayable dominico y, quizá por ello, de difícil consolidación y desigual eficacia ${ }^{53}$.

En cambio, sí concurrió a los actos conmemorativos del tercer centenario de la muerte de Santa Teresa de Jesús -1882-, que tanto interesaban al obispo. Algunos prebendados trabajaron activamente, además, en la pastoral social y

\footnotetext{
52 PaLACIOS Bañuelos, L., Cículos de obreros y sindicatos agrarios en Córdoba (38771923), Córdoba, 1980, 22-23. Vd. ANDRÉs-GalleGo, J., "Los Círculos de Códoba, 1877-1916", Anuario de Historia Moderna y Contemporánea 6 (1979), 125-171, y "La Iglesia y la cuestión social: Replanteamiento", Esiudios históricos sobre la Iglesia española contemporanea. II Sentana de Historia eclesiástica de España contemporánea, El Escorial, [979, 11-115.

53 Cfr. Palacios Bañuelos, L., op. cit., i64-65.
}

De la Iglesia Andaluza Hisparia Sacra 48 (1996) 
en el establecimiento de nuevas comunidades religiosas ${ }^{54}$. La catedral acogió, asimismo, las misiones generales que el ordinario tuvo a bien disponer.

No poco debió contribuir al apacible clima de entendimiento imperante en las relaciones institucionales, el que los encargados de la administración diocesana engrosaran el cuerpo capitular. Paralelamente, Ceferino González contó con un eficaz equipo de colaboradores, consagrado por entero a hacer realidad su programa. De preferencia, nutrió el elenco la plantilla docente y directiva del Seminario, que gozaba, por el común, alguna prebenda. Sobresalieron el rector y canónigo lectoral, Silvestre Pérez Godoy, personaje clave de la etapa y aunténtica mano derecha del mitrado, junto a su relevo en el cargo, el penitenciario Manuel Jerez y Caballero, hasta entonces diputado conciliar y catedrático decano del claustro. También formaron parte del grupo los canónigos Pedro García Llergo, Fernando de Yuste, Juan Vargas y Alejandro del Prado.

Recordemos que fray Ceferino, gran figura del episcopado de la monarquía de Sagunto, resultó elegido senador por los sufragáneos de la archidiócesis hispalense y sus respectivas corporaciones catedralicias, en los comicios de 1877 y 1879. Todos fueron conscientes que en su preconización al arzobispado de Sevilla pesaron sus extraordinarias dotes. Cuando fue presentado, el Cabildo aludió al "merecido ascenso de un Príncipe de la Iglesia tan recomendable por su ciencia y virtud (...) aunque sentia la ausencia del que tan en armonía ha estado con él y las consideraciones que le ha dispensado" 55 . En la carta de despedida a sus diocesanos, el obispo reservó un emocionado recuerdo hacia su consejo: "...damos tambien igual testimonio de agradecimiento á nuestro muy digno Cabildo Catedral por la eficaz y sincera cooperación que nos ha prestado para el gobierno de la Diócesis y para la defensa de los derechos de la Iglesia y de la Santa Sede" 56 . Por aquellas calendas, había quedado ya vertebrada la última restauración religiosa que conociera la Córdoba del XIX.

54 Vd. Zarco Cañadillas, J., "La diócesis de Córdoba en el comienzo del último cuato del siglo XIX", Actas III Coloquio Historia de Andalucia. Historia Contemporánea, Códoba, 1985, J, 302 .

ss ACC.- Actas Capitulares. Cabildo extraordinario, 28 de enero de 1883 , t. 120 , s.f.'

s6 BEC. $5(1883), 199$. 